\title{
Institutions and the Regulation of Business- An International Firm-Level Study of Regulatory Compliance Costs
}

\author{
Gjalt de Jong ${ }^{*}$, Roderick Kloeze \\ University of Groningen, Groningen, The Netherlands. \\ Email: *g.de.jong@rug.nl \\ Received August 27 $7^{\text {th }}, 2013$; revised September 23 $3^{\text {rd }}, 2013$; accepted September $28^{\text {th }}, 2013$ \\ Copyright (C) 2013 Gjalt de Jong, Roderick Kloeze. This is an open access article distributed under the Creative Commons Attribution \\ License, which permits unrestricted use, distribution, and reproduction in any medium, provided the original work is properly cited.
}

\begin{abstract}
Prior work has established the negative effects of many regulations on business and policy.These negative effects have been a key driver for many of the so-called better regulation programmes. Despite all efforts, however, deregulation programmes have had inconclusive results and their success remains the subject of ongoing debate. We suggest that the public policy efforts have largely overlooked a business perspective of regulation and its institutional determinants. We argue that the institutional determinants of regulation include the regulation stock, the quality of regulation and the predictability of regulation application. This study is among the first to examine the impact of these institutional determinants on regulatory compliance costs for firms using a unique dataset from companies in OECD countries. Our results convincingly support our approach to the study of regulation.
\end{abstract}

Keywords: Better Regulation; Compliance Costs; Regulation Stock; Regulation Quality; Regulation Predictability; OECD Countries

\section{Introduction}

Low economic growth and high levels of national debt have increased the interest of governments in structural reforms to boost competitiveness and reduce unemployment. One aspect that often appears in these discussions is cutting red tape, that is, limiting the negative consequences of regulation for business. The drive to reduce red tape actually precedes the current economic difficulties and has received wide attention, especially in Europe [1]. In the US the passing of the Sarbanes-Oxley Act following the Enron scandal also sparked interest in the costs and benefits of government regulation [2,3]. Despite all efforts, however, the success of regulation reducing policies is still the subject of ongoing debate. In this study we delve deeper into the institutional foundations of regulation. We argue that an institutional focus employinga firm-level perspective is a useful approach to the policy debate. We add to existing research by demon strating that from a business perspective, regulation causes compliance costs due to the institutional setting within which a company operates: the stock, quality and

${ }^{*}$ Corresponding author. predictability of regulation.

Our study focuses on the firm-level compliance costs of government regulation. Assessing the situation, Wegrich [1] and Helm [4] conclude that while the volume of the regulation research stream is substantial and the theories on regulation abundant, current conceptualizations and measures of regulation remain inadequate. Accordingly, the regulation research domain is broad, but it has not yet reached maturity and there is a need to reexamine conventional wisdom about regulation. The commonly held view that regulation constrains entrepreneurship and limits welfare has induced policymakers to review their regulatory practices. Today, a reduction in regulatory requirements is on the policy agenda of almost all European countries and international organizations, which is exemplified by the growth in so-called "better regulation programmes" [5]. Despite these programmes, concerns remain that regulation is still negatively impacting firm activities significantly and that deregulation programmes have largely failed [6].

In line with public administration research [7-9], we suggest that firm-level regulation costs are determined by the institutional setting: the stock of existing regulations, 
its quality and its predictability. As convincingly argued in the business literature, managers of private firms form cognitive maps based on perceived information and events, which subsequently impact on a firm's strategic decisions. We therefore propose that effective policy measures need to account for firms' perspective of regulation costs and its institutional determinants. We test our hypotheses on a large sample of small and medium sized enterprises from OECD countries [10]. Our research context is relevant because firms in these countries are increasingly exposed to regulation by governments and international organizations such as the European Union.

The outline of this paper is as follows. We begin by reviewing the research that serves as the foundation for our hypotheses. We discuss definitions, measures and the consequences of red tape in public administration and public policy. Next, building on this theoretical background, we formulate our hypotheses about the institutional drivers of regulatory compliance costs. Then we introduce this paper's research methodology, addressing issues related to our measurement of the variables. Following that, we present our empirical findings. Finally, we conclude by discussing limitations and offering a reflection on opportunities for future research.

\section{Literature Review}

The research tradition in public administration and public policy offers useful insights for the development of our hypotheses and the empirical part of our study. Both adopt the organization as the unit of analysis: the former focuses on government organizations, while the latter concentrates on private companies. When reviewing this literature, at least three conclusions emerge.

First, red tape (i.e., the negative consequences of regulation) is best conceptualized from a firm's perspective. Rosenfeld [11] offered one of the first definitions of red tape as "guidelines, procedures, forms and government intervention that are perceived as excessive, unwieldy, or pointless in relationship to decision-making or implementation of decisions" ([11]: 603). This definition sets out two oft-repeated important characteristics of red tape: red tape as excessive regulation and red tape as a perception or impression. Public administration research has refined Rosenfeld's definition following substantial progress in the empirical study of red tape [12,13]. With variations, the definitions largely align with Bozeman's [7] conceptualization of red tape as "rules, regulations, and procedures that remain in force and entail a compliance burden for the organization but have no efficacy for the rules' functional object" ([7]: 283). Red tape is defined as those rules that serve no purpose at all. It is different from formalization and rules that may have benefits ("white tape"). In a similar vein, we argue that the cost of government regulation is best analyzed from a firm's perspective. This offers a better reflection of the regulatory constraints faced by companies, as well as the degree to which these constraints serve no purpose [13]. This aligns with Feeney and Bozeman's [14] conclusions, who observe that there is an emerging consensus that red tape matters for organizations and this affects firm decisions and behavior in complicated ways.

Second, firm-level data collected by means of surveys permit managers to respond not just to the number of rules and procedures they face, but also to what degree they are oppressive or frustrating $[8,13]$. Business impact studies have generated various measurements for the costs of regulation, enabling the study of the antecedents and consequences of regulation from an international perspective. For example, the World Bank's "Doing Business" indicators investigate the degree and indirect effects of regulation from a cost accountancy perspective $[2,15,16]$. The Standard Cost Method (SCM) quantifies the total costs of administrative procedures [2]. Djankov et al. [17] show that the differences in regulation costs across countries are substantial and that they hamper the entry of new firms and foreign direct investment. This research tradition is based on the institutional view, which argues that economic growth and wealth ultimately depend on a country's institutional framework [18]. North [19] defines these institutions as the "rules of the game" and formal regulation make up a large part of the institutional framework [20].

Third, business impact studies and public administration research also offer insights for the foundations of red tape. If red tape does not serve an organizational purpose and is in effect pointless, then why does red tape exist? Why do organizations and governments not simply eliminate pointless rules and regulations to set the organization or the business community free? Bozeman [21] offers an initial explanation as to why red tape exists in the first place: rules that are viewed as pointless by some may be treasured by others. Bozeman [21] also distinguishes two sources of red tape: "rules born bad" and "good rules gone bad". The former result from inadequate comprehension, self-aggrandizement and over-control. The latter come about through rule drift, rule entropy, change in functional object and misapplication. These explanations all relate to instances where intrinsically good rules are applied in ways not originally intended or to rules whose meaning is lost over time due to inertia or a changing environment.

In a similar vein, Bozeman [21] discusses how political processes can cause rules to be born bad or go bad, with special attention to the influence of the US Congress. One of the causes of red tape is political compromise. The result of political compromise is often vaguely worded regulation intended not to inflame important 
constituencies or interest groups. It is then left to the bureaucracy to refine the language, often leading to regulation which includes unnecessarily many exceptions and caveats, and which goes beyond its originally intended scope. The political process itself also tends to lead to excessive demand for regulation. Interest groups demand regulation to protect or enhance their interests. These groups obtain the benefits of successfully lobbied regulation and, since the costs are borne by the entire population, the private benefits they obtain exceed their private costs [4]. This process causes the level of regulation to exceed what is socially desirable, and the majority of firms will view regulation as excessive and thus as red tape. Finally, excessive regulation is also the result of risk aversion and patronage. Politicians are generally blamed for adverse incidents through a failure to prevent them by means of regulation. They are less often blamed for unnecessary regulation. The result is that risk-averse politicians have an incentive to supply excessive levels of regulation or to require excessive enforcement from the bureaucracy. Politicians also have an incentive to supply regulations that benefit groups that are important during elections. Hence, the political process provides an institutional setting where there is excessive demand for and supply of regulation, resulting in increasing "external" red tape for private firms and "internal" red tape for government organizations.

\section{Hypotheses}

Public administration research and business impact studies offer three antecedents of rule production that we will use to explain regulatory compliance costs. The existing stock of regulation is our first institutional determinant. This aligns with the observation that the stock of regulation is ever increasing, resulting in ever-increasing legal requirements and regulation costs for companies to bear. The design of regulation is our second institutional determinant. The inherent characteristics of the political process explain the production of regulation that is of low quality. The result of compromise can be regulation that is vaguely worded or ambiguous. It is then left to the bureaucracy to refine and implement such regulation, the result of which will be regulation with unnecessarily many exceptions and caveats [4]. The predictability of the enforcement of regulation is our third institutional determinant. Regulation aligns with uncertainty, depending on how rules need to be applied by firms. Ambiguous regulation resulting from political processes $[4,17]$ can result in different interpretations. As a result, the application of rules can differ across firms and sectors.

\subsection{The Existing Stock of Regulation}

Various studies following Djankov et al. [17] show that the costs of administrative procedures can be substantial [16]. The average number procedural steps needed to start a business in the sample of Djankov et al. [17] was 10.48, taking at least 47.40 business days. The costs of these procedures were estimated at an average of $47.08 \%$ of per capita GDP. These costs slow the rate of new business entry [22]. The existing stock of regulation is a determinant of compliance costs, as the compliance with existing rules is a legal requirement on firms. Feeney and Bozeman [14], in a study of internal red tape, found that those respondents who felt that the focal organization had too many rules also perceived higher levels of organizational and contractual red tape. There are two explanations for this. First, if the number of rules that need to be complied with is higher, the number of rules felt to be excessive or obsolete and their share of the overall population of rules will also be larger. Second, the more rules a manager needs to comply with, the more likely a manager will be to consider this to be a frustrating process resulting in a general opinion that all rules are pointless or excessive-rules end up being considered as causing red tape even when strictly speaking they do not [13]. Taking the above into account, we formulate our first hypothesis:

Hypothesis 1 (H1): The larger the existing stock of regulation, the larger the compliance costs of regulation.

\subsection{The Quality of Regulation Design}

The second institutional variable in our study concerns the quality of regulation design. This variable encompasses several dimensions of quality, such as the ease of understanding rules and procedures, whether or not it is clear which agency to contact and whether the rules are designed to achieve their objective as effectively as possible. One of the main criticisms of both the World Bank and the SCM measurements of the costs of regulation is that these treat all regulation as inherently negative and do not account for the design of regulation in the first place $[6,15]$. Radaelli [5] argues that "[t]he concept of quality has now become a fundamental component of regulatory reform and regulatory management in a large number of countries" ([5]: 271). Furthermore, DeHartDavis [23] found that well-designed rules are less likely to be considered as "red tape" and more likely as "green" or "white" tape. Hence, if regulation is well designed, the firm-level negative effects of regulation will be lower. Additionally, the discussion of "rules bornbad" [21] shows that the design of regulation is a key determinant of red tape. These are all reasons why low-quality regulation increases the company's costs of regulation. Better quality should reduce the costs of regulation for various reasons. First, if rules are easy to understand and it is clear whoin government to contact about them, the time spent by business in complying with regulation is re- 
duced. Moreover, rules that are easy to understand reduce the inclination to seek and the need for outside legal expertise. To put it differently: regulation with mediocre design increases the costs of "transacting" with the government. Since compliance with regulation is a "transaction" that cannot be legally avoided, it raises the costs of regulation. This leads to the following hypothesis:

Hypothesis 2 ( $\mathrm{H} 2)$ : A higher quality of regulation design lowers the compliance costs of regulation.

\subsection{Predictability of Regulation Application}

The final institutional variable of our study concerns the predictability of the application of existing regulation. Intuitively, if regulation is applied consistently and is therefore predictable, the costs of regulatory compliance for a company should be lower. The consistent application of regulation means that companies, for example, will know what forms to complete and how. This reduces regulatory uncertainty. Lower uncertainty means firms will be less likely to hire outside expertise in complying with regulation. Further, the chance of litigation as a result of not complying with regulation is reduced. Bertelli and Whitford [24] find that rules to be of better quality in terms of protecting market mechanisms, if an independent regulator enforces them. Independent regulators can apply rules and regulation more consistently and predictably than regulators who are under political pressure. Consistency of application enhances the predictability of enforcement of regulation and is one of the characteristics of green tape identified by DeHart-Davis [23]. As with regulation quality, the costs of "transacting" with the government decreases if regulation application and enforcement is more predictable. Transaction cost economics argues that a transaction characterized by high uncertainty should either be internalized or there should be unilateral adaptation [25]. By definition, however, a transaction with a regulatory body cannot be internalized. Therefore, the increased transaction costs due to inconsistent and unpredictable adaptation of regulation have to be borne by the firm. This leads to the following hypothesis:

Hypothesis 3 (H3): The more predictably that regulation is enforced, the lower the compliance costs of regulation.

\section{RESEARCH METHODS}

\subsection{Data and Sample}

The data used in this study derives from the OECD [10] study of regulation. The database presents survey-based information from nearly 8000 small and medium sized firms in 11 OECD countries. It offers information with respect to three areas of regulation. The first area is employment regulation, which includes hiring and firing employees, complying with health and safety standards, workers rights, consulting with worker councils or unions, statistical reporting of employment-related data, administering employment-related or payroll taxes, social security and pensions, or other mandatory employee benefits such as maternity leave and sick leave. These second area is environment regulation, which includes licenses, permits, planning and environmental impact assessments; complying with emission/discharge and hazardous substance requirements, process or product quality standards, pollution control and product regulations; environmental reporting and testing, record-keeping and day-to-day administrative requirements related to the environment, such as environmental levies and taxes; and eco-labelling of products or processes. The third area is tax regulation, which includes business profits tax/ corporate income tax, other taxes on capital and assets (e.g. dividend tax, property tax), sales taxes (e.g. VAT, general sales taxes), and tax deduction requests such as PAYE income taxes. These areas of regulation cover the most important national and international business rules imposed by governments and international organizations.

The focus of the survey was on firms that employ 500 employees or less. The choice of these firms as the unit of analysis is appropriate for two main reasons. First, it has been argued that small and medium sized firms are more exposed to regulation than their larger counterparts. The performance and strategic decision-making behaviour of small and medium sized firms is more sensitive to regulation than large firms. Second, large firms experience greater difficulty in responding to a regulation survey as no single person or department is responsible for compliance with all regulation to which a large firm is exposed. Large firms also have international activities, further complicating the measurement of regulation.

The survey was distributed by mail in 11 OECD countries: Australia, Austria, Belgium, Finland, Iceland, Mexico, Norway, New Zealand, Portugal, Spain and Sweden. Each firm in the sample received a single questionnaire on either labour, environmental or tax regulation. No single respondent thus provided information on all areas of regulation. The overall response rate of $40 \%$ was satisfactory, with response rates ranging from a high of $78 \%$ in Australia, to a low of $18 \%$ in Mexico and Portugal, respectively. We pooled the firm-level information in one database and used country dummies to control for international differences in costs of regulation. This procedure ensures a sufficient number of observations to obtain reliable estimates of our hypothesized relationships.

\subsection{Measurements: Dependent Variable}

Our measure of regulation costs aligns with the standard cost method. The SCM measurement of regulation costs 
accounts for different cost components of regulation. The compliance costs of regulation for a firm are determined by a) the number of hours spent by staff and management ("Estimate the number of hours spent in an average month by staff and management in your business complying with regulations"), b) expenditure on computers and software ("Estimate your annual computer or software expenditure which is principally used to comply with regulations"), and c) the expenditure on hiring outside expertise ("How much money does your business spend during an average month on hiring outside services to comply with regulations"). To obtain yearly estimates and to obtain consistency within the second item, we multiplied the first and the third items by twelve. Further, in line with the SCM method, the first item was multiplied by the hourly labour costs per country (firm-level data for hourly labour costs was not available). The three different components of regulatory compliance costs were aggregated in an overall measurement of regulation costs. We used the logarithm of these costs to obtain a normally distributed measurement of our dependent variable.

\subsection{Measurements: Independent Variables}

We use a composition of two survey items to obtain our measurement of the existing stock of regulation (see Djankov et al. [17] for a similar approach). The first item is a count of the number of government decisions that the company had to comply with ("During the past year, how many separate decisions or permits did your business request from a government to comply with regulations?"). However, some rules are more complex and thus need more time and attention to comply with than others. A single count of regulations would insufficiently account for differences in complexity per regulation. We therefore used a second item to correct for this. The second item measures the degree to which it is feasible to comply fully with all relevant regulations, despite their number ("Regardless the number of regulations, is it still feasible to comply with them fully?"). The first item is a continuous variable and the responses range between 0 and 300. We multiplied this item by the inverse of the second item and used the resulting weighted scale as our measurement for the stock of regulation that a firm faces. This means that the number of rules and procedures in the stock of regulation will be weighted lower, the more feasible it is to comply with them.

We use respondents' evaluation of three statements to measure the quality of regulatory design: "regulations are easy to understand", "regulations achieve their objectives as simply as possible", and "regulations are consistent with one another". Each was measured on a four-point Likert scale, with categories ranging from $1=$ "agree fully" to $4=$ "disagree fully". These items directly relate to Bozeman's [21] conceptualization of red tape and to the characteristics of high quality regulation [4,5]. A factor analysis confirmed the uni-dimensionality of the three-item scale. The Cronbach's alpha of 0.71 is above the threshold value of 0.70 and is therefore satisfactory. We combined the three items into an overall index of regulatory design quality.

We used the respondents' evaluation of the following five statements to measure the consistency and predictability of regulations, introduced by "thinking about your contacts with government offices to obtain decisions or permissions on regulations, to what extent to you agree or disagree with the following statements": "officials give definite answers", "it is clear who is responsible for decisions", "the process for appeals and complaints is clear", "decisions are consistent and predictable over time and among similar businesses", "additional or unexpected payments are not required", and "you get the same view no matter who you contact". Each was measured on a four-point Likert scale, with categories ranging from 1 = "agree fully" to $4=$ "disagree fully". The items directly relate to the requirements of consistent regulation $[5,15,17]$. A factor analysis confirmed the uni-dimensionality of the five-item scale. The Cronbach's alpha of 0.72 is above the threshold value of 0.70 and is therefore satisfactory. We combined the five items into an overall index of regulation consistency.

\subsection{Control Variables}

We entered various control variables when we tested the hypothesized relationships. The first control variable is the size of the firm. It is known that the compliance cost of regulation is usually a fixed cost, meaning that the burden is smaller for a large firm than for a small firm $[2,26]$. In fact, it is suggested that compliance costs are the highest for medium sized firms and the smallest for very small or very large firms. We therefore include firm size and the squared term of firm size in our model to account for the inverted U-shaped relationship between firm size and compliance cost. The number of employees measures firm size. The second control variable is the age of the firm. Compliance costs vary with the age of the company in its overall lifecycle. Older companies will have learned how to deal with bureaucratic procedures. They are therefore less likely to bear the negative effects of regulation and may have developed methods and procedures to efficiently deal with regulation [9]. The age of the company is measured by an ordinal measure ranging from 1 to 3 , with 1 indicating firms that are less than two years old, 2 indicating firms between two and five years old, and 3 firms older than five years old. The third control variable is a dummy variable that measures whether or not a foreign company owns the firm. Foreign ownership could mean that the firm experiences more compliance costs because it has to com- 
ply with particular host country regulation that does not apply to the home country. Fourth, we control for the company's sector. Regulation differs across sectors within a country. Thefirms operate in 16 different sectors. We added 15 dummy variables to account for sector differences. Fifth, the firms offered information for each of the three main regulation areas (i.e., employment, environment and tax regulations). Differences in regulation areas could exist and firmscouldconsider regulatory compliance costs in certain areas to be higher than in others. We include regulation area dummies to control for this. Finally, we include country dummies to control for country-specific differences in regulation costs that are not captured by the independent variables in our model.

\section{Empirical Results}

\subsection{Main Findings}

Means, standard deviations and correlations are provided in Table 1. In preparation for the regression analyses, we performed the usual tests to obtain reliable estimates. These tests show that non-normality is not an issue. We tested for possible biases caused by collinearity among variables by calculating the variance inflation factor (VIF) for each of the regression coefficients. Calculations of VIF ranged from a low of 1.1 to a high of 1.5. The VIF values were well below the cut-off value of 10 [27]. The pretests indicate that heteroscedasticity might be present in the data. We therefore estimated our model with robust standard errors, which is the usual solution for this [27]. Table 2 presents the regression results.

We ran a two-step hierarchical regression: that is, the three regulation dimensions were added in Model 2 to Model 1 with control variables. The dependent variable is a logarithm of compliance costs so the coefficients denote percentage changes. The various fit parameters show that our full model fit the data better. The $R^{2}$ improves from 47 percent in Model 1 to 49 percent in Model $2(F=92.48$ with $p<0.001$ and $F=93.23$ with $p$ $<0.001$ for Models 1 and 2, respectively). Taken to- gether, our results offer strong support for two of our three hypotheses and modest support for the other. Table 2 shows that the existing stock of regulation has a positive and strongly significant effect on compliance costs ( $\beta=0.021$, with $p<0.001)$. Hypothesis 1 is thus confirmed. The magnitude of the coefficient of the regulation stock variable is also significant. Depending on the ease of compliance, on average, each extra rule increases the company's costs of regulatory compliance by between $0.53 \%$ and $2.1 \%$ (if the number of rules and procedures that a firm has to comply with is not adjusted for the feasibility of compliance, the results are nearly identical). The average firm in our sample faces compliance costs of approximately USD 380,000 per year. One extra rule increases regulatory compliance costs by approximately USD 2000 if the ease of compliance is at its highest level (a score of 4) and by approximately USD 8000 if the ease of compliance is at its lowest level (a score of 1 ).

Hypothesis 2, predicting that a higher quality of regulation design will reduce the company's costs of regulatory compliance, is also confirmed. The coefficient is strongly significant and the sign is negative, as expected $(\beta=-0.124$ with $p<0.001)$. The size of the coefficient also is large, here estimated at $12.4 \%$. The scale of this variable ranges from 3 to 12 : everything else being equal, the compliance costs of regulation for a firm that faces the lowest quality of regulation design (a score of 3) is 112 percent higher than that of a firm that faces the highest quality of regulation design (a score of 12). For the average firm this means a difference of almost USD 425,000 . Hypothesis 3 , predicting that a greater predictability of regulation application will lower the compliance costs of regulation, is also confirmed. The coefficient receives moderate support and is negative, as expected $(\beta=-0.031$ with $p<0.05)$. The size effect of the coefficient is somewhat smaller than that of the quality variable, but at $3.1 \%$ it is still substantial. The regulation predictability variable ranges from 5 to 20 ; everything else being equal, the difference in the cost of regulatory

Table 1. Correlations, means and SDs ${ }^{(\mathrm{a})}$.

\begin{tabular}{|c|c|c|c|c|c|c|c|c|c|c|}
\hline & Mean & SD & 1 & 2 & 3 & 4 & 5 & 6 & 7 & 8 \\
\hline Regulation Costs (log) & 2.66 & 8.20 & 1.000 & & & & & & & \\
\hline Regulation Stock & 5.02 & 12.03 & 0.127 & 1.000 & & & & & & \\
\hline Regulation Quality & 6.37 & 1.88 & -0.027 & -0.143 & 1.000 & & & & & \\
\hline Regulation Predictability & 11.10 & 2.70 & -0.035 & -0.064 & 0.473 & 1.000 & & & & \\
\hline Firm Size & 67.18 & 104.63 & 0.161 & 0.101 & 0.011 & 0.110 & 1.000 & & & \\
\hline Firm Size Squared & 2.87 & 0.39 & 0.088 & 0.068 & 0.002 & 0.089 & 0.898 & 1.000 & & \\
\hline Firm Age & 2.87 & 0.39 & 0.031 & 0.024 & -0.054 & -0.054 & 0.070 & 0.035 & 1.000 & \\
\hline Foreign Ownership & 0.13 & 0.33 & 0.124 & 0.082 & -0.031 & 0.051 & 0.226 & 0.142 & 0.000 & 1.000 \\
\hline
\end{tabular}

Notes: ${ }^{(a)}$ Paired correlations of the main variables. 
Table 2. The determinants of perceived regulatory compliance costs ${ }^{(a)}$.

\begin{tabular}{|c|c|c|}
\hline & $\begin{array}{l}\text { Model } 1 \\
\text { Regulatory Compliance Costs }\end{array}$ & $\begin{array}{l}\text { Model } 2 \\
\text { Regulatory Compliance Costs }\end{array}$ \\
\hline \multirow[t]{2}{*}{ Regulation Stock } & & $0.021^{* * *}$ \\
\hline & & $(0.005)$ \\
\hline \multirow[t]{2}{*}{ Regulation Quality } & & $-0.124^{* * *}$ \\
\hline & & $(-0.019)$ \\
\hline \multirow[t]{2}{*}{ Regulation Predictability } & & $-0.031^{*}$ \\
\hline & & $(-0.013)$ \\
\hline \multirow[t]{2}{*}{ Firm Size } & $0.008^{* * *}$ & $0.008^{* * *}$ \\
\hline & $(0.001)$ & $(0.001)$ \\
\hline \multirow[t]{2}{*}{ Firm Size Squared } & $-0.000^{* * *}$ & $-0.000^{* * *}$ \\
\hline & $(0)$ & $(0)$ \\
\hline \multirow[t]{2}{*}{ Firm Age } & 0.133 & 0.109 \\
\hline & $(0.084)$ & $(0.083)$ \\
\hline \multirow[t]{2}{*}{ Foreign Ownership } & $0.309^{* *}$ & $0.284^{* *}$ \\
\hline & $(0.104)$ & $(0.102)$ \\
\hline \multirow[t]{2}{*}{ Constant } & $11.906^{* * *}$ & $13.025^{* * *}$ \\
\hline & $(0.467)$ & $(0.473)$ \\
\hline Observations & 2990 & 2990 \\
\hline R-squared & 0.47 & 0.49 \\
\hline Adjusted R-squared & 0.46 & 0.49 \\
\hline F-value & $92.48^{* * *}$ & $93.23^{* * *}$ \\
\hline
\end{tabular}

Notes: ${ }^{(a) \dagger} p<0.10,{ }^{*} p<0.05,{ }^{* *} p<0.01,{ }^{* * *} p<0.001$. Robust standard errors in parentheses. Sector, regulation area and country dummies are included in the model.

compliance from the lowest to the highest quality is $46.5 \%$. For the average firm, this means a difference of almost USD 177,000.

Our results for regulation hold, whilst controlling for a large number of alternative antecedents that may determine a company's compliance costs. With regard to the control variables, one result is worth mentioning. The size of the firm (measured by the number of employees) is a significant predictor of the compliance costs of regulation. Larger firms face higher costs of compliance than smaller firms. This effect diminishes somewhat as firms grow larger, but not by much (the coefficient for the square of number of employees is relatively small). This aligns with the firms included in this sample, which all have 500 employees or less. Nonetheless, a non-monotic relationship between firm size and regulation costs appears.

\subsection{Robustness Analysis}

We conducted further analyses to assess the robustness of our results. The results were largely consistent with the initial results in each of these supplemental analyses.
First, we disaggregated the data in the three different regulatory areas that are included in our study. These results support the conclusion that the existing regulation stockand the quality of regulation design are important determinants of a company's compliance costs. However, the estimated parameter coefficient for regulation predictability is only significant in the domain of tax regulation. Apparently, unpredictability in the application of regulation is an important matter of concern for tax regulation. Intuitively, this makes sense: for many companies, compliance with taxation rules will be of the utmost importance, given the penalties involved for not meeting regulatory requirements in this area. Firms will be strongly inclined to align with tax regulation. The unpredictability of application is therefore likely to be a greater source of concern with regard to taxation, where unintended violations of rules can have more serious consequences than in other areas of regulation. Second, we disaggregated compliance costs into its underlying cost components. All of our hypotheses were reconfirmed. We also found that the regulatory structure is particularly important to the costs of external support, and less so to ICT expenses. Software or ICT costs are 
usually incidental investments: it is likely that they are made in response to structural issues rather than in response to issues that can change from year to year. Third, we estimated our models using generalized least squares (GLS). GLS is another method that corrects for heteroskedasticity, by weighting the least squares errors so that they become homoskedastic [27]. This did not affect the results at all. Hence, the regression studies and the robustness analyses are strongly convincing and are consistent with our institutional explanation of regulatory compliance costs for firms.

\section{Recommendations and Limitations}

Over time, each country has developed its own country-specific regulatory infrastructure. This results in substantial cross-country differences in average compliance costs for firms. For example, firms in Spain and Portugal face regulatory compliance costs 240 times as large as those in New Zealand. Previous research has established that such differences can explain differentials in national economic outcomes [22,28]. Large regulatory burdens and restrictive regulation are among the most important causes of the economic under-performance and stagnation of Mediterranean economies compared to other countries.

Our study provides evidence in favour of the hypothesis that an increase in the existing stock of regulation increases the compliance costs of regulation for firms. The increase in regulatory compliance costs is greatest if firms consider the regulatory burden to already be so large that it is no longer feasible to comply with all regulation. However, even when it is feasible to comply with all regulation, an increase in the number of rules and procedures faced by firms leads to an increase in compliance costs of about $0.5 \%$. Therefore, all regulation leads to costs and each new rule or procedure increases the administrative burden faced by firms. The regulatory compliance costs identified in this study are substantial and potentially underestimated. A firm that makes ICT investments to comply with regulation cannot use these resources for alternative and perhaps more productive processes. Employees spending time on meeting regulatory requirements cannot perform alternative tasks. Our results are an indication to policymakers that any rule they design and implement will involve costs for those they apply to.

The results with regard to the quality of design are also robust. Whereas it is debatable whether a large stock of regulation is beneficial or not, there is less ambiguity with regard to the quality of regulation. An increase in the quality of regulation lowers compliance costs and is of direct benefit to society. The effect is substantial: each point increase on our scale of regulation quality (ranging from 3 to 12) decreases the compliance costs of regula- tion by $10 \%$ to $12 \%$. The benefits to society will perhaps be somewhat smaller than those to individual firms because the process of drafting high quality regulation can be long and costly. However, given the fact that low quality regulation impacts all firms and that the reduction in costs is large, the net effect is likely to be beneficial. The robustness tests have shown that the effects of regulation quality are especially strong for ICT investments. The implication is that an improvement in regulation quality will free resources that firms can use for alternative investments, which in turn can have economic benefits for the firm and for the country.

The results with regard to the predictability of regulation application also lead to interesting conclusions. The results indicate that a reduction in unpredictability leads to a reduction in the compliance costs of regulation for firms. The result of a reduction in unpredictability is thus a gain to business, at the costs of extra legislative resources. On balance, this again is likely to offer net social gains, albeit with beneficial effects that are smaller than those of an increase in regulation quality. The benefits firms accrue are approximately $2 \%$ to $3 \%$ for each point increase on our regulation predictability scale (ranging from 5 to 20). We found that the effects of regulation predictability mainly materialize in tax regulation. A country with high tax regulation compliance costs should focus on the improvement of regulation application in this domain first.

This study advances the public policy literature by using data to investigate compliance costs at the firm level, in a cross-country setting. The use of firm-level data is well established in public administration research for the study of internal red tape and the effects thereof on organizational outcomes. Regulation in business impact studies is generally studied using country-level data on the number of rules that firms have to comply with (according to the official rule book). This study therefore expands the latter line of research by examining actual compliance costs and the actual number of rules faced by firms. Not all firms have to comply with all regulations. Compliance and enforcement may be spotty, so that the actual number of rules that need to be complied with differs from what an analysis of existing legislation would suggest. Previous country studies implicitly assume that regulation is the same for all firms in a given country. The data used here show wide variations in regulation costs within countries as well as between countries.

This study adds two qualitative dimensions to the regulation debate: namely, regulation quality and regulation application predictability. These are not included, at least not explicitly, in previous work on regulation [15]. The present study considers regulation as a multi-dimensional concept. The results show that our dimensions 
have a significant and substantial impact on the compliance costs faced by firms. Ignoring such factors will thus misinform the policymakers who design measures aimed at reducing the costs of regulation.

\subsection{Policy Recommendations and Managerial Implications}

This study has implications for policymakers and managers. The first implication follows directly from the observation that quality and predictability are determinants of the costs of compliance for companies in addition to the stock of regulation. Policymakers who want to reduce regulation costs for firms are advised to primarily consider the design and application of the rules they implement, for two reasons. First, policymakers who introduce new regulation should be aware that even well-intended regulations with social benefits can result in high costs for firms. New regulations can result in a net social loss if they are poorly designed or inadequately applied. Further, new rules are often created in response to incidents. Policymakers anticipating incidents with new regulation, often only consider the benefits of these new rules inasmuch as they prevent the recurrence of the initial incident. Regulation is often implemented following incidents that never recur. In such cases, the costs of regulation easily exceed the envisioned benefits. The Sarbanes-Oxley Act is an example of such a case. Our results are therefore an appeal to abstain from incident politics. The design of regulation in incident situations is likely to be of poor quality due to the short time horizons of policymakers in such situations. Incident politics will also result in ad hoc regulation without a coherent view of all the regulation already imposed upon firms.

Second, for those policymakers seeking to reduce the compliance costs for firms of existing regulation, the return on political capital is likely to be higher in terms of improving regulation quality or regulation predictability than of reducing the stock of regulation. As Kaufman [29] has argued: “[O]ne person's red tape may be another's treasured safeguard" ([29]: 4). Every rule or procedure that is removed will meet opposition from one constituency or another. Improvements in quality and predictability will be largely uncontroversial. A policymaker with limited time and resources can therefore have a greater impact on compliance costs for firms by improving quality and predictability rather than by removing rules from the stock of regulation.

For managers, the implications in part parallel those for policymakers. The efforts to influence policymakers could focus on improving regulation quality and regulation predictability alongside and in addition to regular lobbying activity to reduce or prevent new regulation. The implications for managers also mirror those of poli- cymakers in the design and application of internal bureaucracy. Our study focuses on regulatory compliance costs. The constituent parts of this external red tape (regulation costs, stock, quality and predictability) can also apply to internal red tape with similar causal relationships. Finally, our results show that the costs of regulation vary between countries, resulting in different rates of return of foreign direct investment. Our results also indicate that foreign firms face higher compliance costs of regulation than domestic firms. These compliance costs of regulation for foreign firms directly contribute to the so-called liabilities of foreignness. For managers making foreign direct investment decisions, the compliance costs of regulation should be an important criterion in choosing a new host country.

\subsection{Limitations and Future Research}

Regulation studies have their limitations and our study is no exception. These limitations offer opportunities for future research. A first limitation concerns our measurement of bureaucracy by means of regulatory compliance costs. As Bozeman [7] has argued, bureaucracy and regulation detail are distinct concepts and should not be confused. Our data does not enable the measurement of "net" effects of regulation: an ideal measure of "net" effects of regulation would account for all the costs and benefits of regulation, ultimately measuring only the regulation that is meaningless and unnecessary. Future research could replicate this study using measurements that account for the compliance costs of pointless or useless rules. Another limitation of our empirical study concerns country coverage. The sample is relatively large for a questionnaire-based study of regulation. The observations include countries ranging from Southern Europe and Latin America to Scandinavia and more Anglo-Saxon regions. Nonetheless, we do not know if our results and conclusions also hold for non-OECD countries. Future research could replicate our study with data from Asian countries or for countries with weak institutional infrastructures such as Russia. The final limitation of our empirical study is the cross-sectional nature of the database. A panel dataset would enable longitudinal analyses and in so doing, the study of whether regulatory compliance costs and their institutional determinants vary over time.

New data collection would also enable the study of other institutional determinants of compliance costs, such as the accountability of the agencies responsible for regulation, the degree of regulation enforcement and the speed of regulation introduction. For example, if government agencies were accountable for regulation production or regulation enforcement, this would improve both regulation quality and regulation predictability, reducing 
the regulatory compliance costs for firms. Stronger regulation enforcement will increase regulatory compliance costs because firms will ensure that they comply with all the regulations they face. The speed at which proposed regulation is introduced could reduce regulatory compliance costs because regulation uncertainty for firms would thereby be reduced, preventing unnecessary investments in ICT or external expertise required to anticipate ambiguous regulation situations. Another avenue for future research concerns the costs of compliance due to industry standards (such as ISO certification) or self-regulation. A study of these compliance costs could be valuable for two reasons. First, self-regulation often substitutes for national regulation, potentially reducing the overall regulatory compliance costs for firms. Second, the determinants and effects of industry standards or self-regulation can differ from government regulation.

\section{Conclusion}

In conclusion, regulation dominates world business and a thorough understanding of its determinants remains central to public administration and policy research. With the above limitations acknowledged, we are confident that this study makes an important contribution to this line of research by shedding light on the murky world of the institutional regulatory environment, and adding to our understanding of how the relationships between the various dimensions of the regulatory environment and compliance costs vary.

\section{REFERENCES}

[1] K. Wegrich, "The administrative burden reduction policy boom in Europe: comparing mechanisms of policy diffusion," CARR Discussion Papers, DP 52, London School of Economics and Political Science, London, 2009.

[2] E. Engel, R. M. Hayes and X. Wang, "The SarbanesOxley Act and Firms' Going-Private Decisions," Journal of Accounting and Economics, Vol. 44, No. 1, 2007, pp. 116-145. http://dx.doi.org/10.1016/j.jacceco.2006.07.002

[3] I. X. Zhang, "Economic Consequences of the SarbanesOxley Act of 2002," Journal of Accounting and Economics, Vol. 44, No. 1, 2007, pp. 74-115. http://dx.doi.org/10.1016/j.jacceco.2007.02.002

[4] D. R. Helm, "Regulatory Reform, Capture, and the Regulatory Burden," Oxford Review of Economic Policy, Vol. 22, No. 2, 2006, pp. 169-185. http://dx.doi.org/10.1093/oxrep/gri011

[5] C. M. Radaelli, "Getting to Grips with Quality in the Diffusion of Regulatory Impact Assessment in Europe," Public Policy and Management, Vol. 24, No. 5, 2004, pp. 271-276.

[6] T. Keyworth, "Measuring and Managing the Costs of Red tape: A Review of Recent Policy Developments," Oxford Review of Economic Policy, Vol. 22, No. 2, 2006, pp.

\section{0-273. http://dx.doi.org/10.1093/oxrep/grj016}

[7] B. Bozeman, "A Theory of Government 'Red Tape'," Journal of Public Administration Research and Theory, Vol. 3, No. 3, 1993, pp. 273-304.

[8] B. Bozeman and M. K. Feeney, "Rules and Red Tape. A Prism for Public Administration Theory and Research," ME Sharp, New York, 2011.

[9] S. K. Pandey and P. G. Scott, "Red Tape: A Review and Assessment of Concepts and Measures," Journal of Public Administration Research and Theory, Vol. 12, No. 4, 2002, pp. 553-580. http://dx.doi.org/10.1093/oxfordjournals.jpart.a003547

[10] OECD, "Business Views on Red Tape: Administrative and Regulatory Burdens on Small and Medium-Sized Enterprises," OECD, Paris, 2001.

[11] S. K. Pandey and G. A. Kingsley, "Examining Red Tape in Public and Private Organizations: Alternate Explanations from a Social Psychological Model," Journal of Public Administration Research and Theory, Vol. 10, No. 4, 2000, pp. 779-799. http://dx.doi.org/10.1093/oxfordjournals.jpart.a024291

[12] J. N. Baldwin, "Perceptions of Public versus Private Sector Personnel and Informal Red Tape: Their Impact on Motivation," American Review of Public Administration, Vol. 20, No. 1, 1990, pp. 7-28.

http://dx.doi.org/10.1177/027507409002000102

[13] G. A. Brewer and R. M. Walker, "Explaining Variation in Perceptions of Red Tape: A Professionalism-Marketization Model," Public Administration, Vol. 88, No. 2, 2010, pp. 418-438. http://dx.doi.org/10.1111/j.1467-9299.2010.01827.x

[14] M. K. Feeney and B. Bozeman, "Stakeholder Red Tape: Comparing Perceptions of Pubic Managers and Their Private Consultants," Public Administration Review, Vol. 69, No. 4, 2009, pp. 710-726. http://dx.doi.org/10.1111/j.1540-6210.2009.02019.x

[15] B. Arruñada, "Pitfalls to Avoid When Measuring Institutions: Is Doing Business Damaging Business?" Journal of Comparative Economics, Vol. 35, No. 4, 2007, pp. 729747. http://dx.doi.org/10.1016/i.jce.2007.08.003

[16] W. Harrington, R. D. Morgenstern and P. Nelson, "On the Accuracy of Regulatory Cost Estimates," Journal of Policy Analysis and Management, Vol. 19, No. 2, 2000, pp. 297-322.

http://dx.doi.org/10.1002/(SICI)1520-6688(200021)19:2< 297::AID-PAM7>3.0.CO;2-X

[17] S. Djankov, R. La Porta, F. Lopez-de-Silanes and A. Shleifer, "The Regulation of Entry," Quarterly Journal of Economics, Vol. 117, No. 1, 2002, pp. 1-37. http://dx.doi.org/10.1162/003355302753399436

[18] E. Helpman, “The Mystery of Economic Growth," Harvard University Press, Cambridge, 2004.

[19] D. North, "Institutions, Institutional Change and Economic Performance," Cambridge University Press, Cambridge, 1990.

http://dx.doi.org/10.1017/CBO9780511808678

[20] W. R. Scott, "Institutions and Organizations," Sage Publications Ltd., Thousand Oaks, 2001. 
[21] B. Bozeman, "Bureaucracy and Red Tape," Prentice Hall, Upper Saddle River, 2000.

[22] A. Ciccone and E. Papaioannou, "Red Tape and Delayed Entry," Journal of European Economic Association, Vol. 5, No. 2-3, 2007, pp. 444-458. http://dx.doi.org/10.1162/jeea.2007.5.2-3.444

[23] L. DeHart-Davis, "Green Tape: A Theory of Effective Organizational Rules," Journal of Public Administration Research and Theory, Vol. 19, No. 2, 2009, pp. 361-384. http://dx.doi.org/10.1093/jopart/mun004

[24] A. M. Bertelli and A. B. Whitford, "Perceiving Credible Commitments: How Independent Regulators Shape Elite Perceptions of Regulatory Quality," British Journal of Political Science, Vol. 39, No. 3, 2009, pp. 517-537. http://dx.doi.org/10.1017/S0007123409000623
[25] , O.E. Williamson, "Economic Institutions of Capitalism," Free Press, New York, 1985.

[26] H. G. Rainey, S. K. Pandey and B. Bozeman, "Research Note: Public and Private Managers' Perceptions of Red Tape," Public Administration Review, Vol. 55, No. 6, 1995, pp. 567-574. http://dx.doi.org/10.2307/3110348

[27] R. C. Hill, W. E. Griffiths and G. C. Lim, "Principles of Econometrics," 3rd Edition, John Wiley and Sons, London, 2008. http://dx.doi.org/10.1162/1542476054430834

[28] A. Alesina, S. Ardagna, G. Nicoletti and F. Schiantarelli, "Regulation and Investment," Journal of the European Economic Association, Vol. 3, No. 4, 2005, pp. 791-825.

[29] H. Kaufman, "RedTape: Its Origins, Uses, and Abuses," Brookings, Washington, D.C., 1977. 